\title{
CUSTOS NA REDE PRÓPRIA DE OPERADORA GAÚCHA DE PLANOS DE SAÚDE
}

\author{
COST FOR A GAÚCHA HEALTH PLAN OPERATOR
}

\author{
DALVA SALVALAIO \\ Mestre em Ciências Contábeis pela \\ Universidade do Vale do Rio dos Sinos \\ São Leopoldo/RS, Brasil \\ E-mail: dalva.s@terra.com.br
}

\author{
MARCOS ANTONIO DE SOUZA \\ Doutor em Controladoria e Contabilidade pela \\ Universidade de São Paulo \\ Professor Titular do Centro de Ciências Econômicas da \\ Universidade do Vale do Rio dos Sinos \\ São Leopoldo/RS, Brasil \\ E-mail: marcosas@unisinos.br
}

\section{Resumo}

Este estudo apresenta um sistema de custeio para a rede própria de uma operadora gaúcha de planos de saúde. Identifica o custo por tipo de serviço e compara o resultado com o preço cobrado por uma rede credenciada. Trata-se de uma pesquisa qualitativa, de natureza descritiva e desenvolvida por meio do método de estudo de caso único. $\mathrm{Na}$ mensuração de custos utilizou-se o método de custeio pleno, aplicando-o em uma unidade de atendimento da operadora. Confirma-se que o sistema proporciona informações gerenciais relevantes que auxiliam no processo de tomada de decisão. A análise comparativa do custo apurado na rede própria com o preço do serviço na rede credenciada permite concluir que a opção pela verticalização apresenta-se mais vantajosa.

Palavras-chave: custos; planos de saúde; rede própria; rede credenciada.

\begin{abstract}
This study aims to structure a cost system for a gaúcha health plan operator's own network. Identify the cost by type of service, and compare the result with the price charged by the local accredited network. It is a qualitative research, of an explicative nature, developed through a case study method. In order to size the costs, it was used the full cost system, which was applied in one of the operator's service branch. The conclusion is that the cost system gives managerial information, which helps in the decision-making process and comparing the cost calculated in the own network, with the price of the service in the accredited network, it becomes possible to identify whether the operator's choice for vertical integration service presents more advantages for the company than outsourcing.
\end{abstract}

Key words: costs, health plan, own network, accredited network. 


\section{INTRODUÇÃO}

O mercado de saúde suplementar no Brasil, formado por empresas privadas que operam planos de saúde, surgiu na década de 1970 e ganhou espaço devido à crescente crise da saúde pública no país.

Nessa época os planos comercializados não eram padronizados, os contratos eram elaborados para atender à necessidade de cada cliente, sendo estabelecido apenas um atendimento básico a todos os participantes, indistintamente.

Como a diversidade dos contratos e das coberturas oferecidas era muito variada, os beneficiários ficavam sem saber quais eram os direitos que tinham com o seu plano de saúde. Identificando essa dificuldade no mercado, o Governo Federal resolveu intervir e, por meio da Lei $n^{\circ} 9.656 / 98$, determinou regras para os planos de saúde e para as empresas que os comercializam. Em 2000 foi criada a Agência Nacional de Saúde Suplementar - ANS, com o objetivo de monitorar e fiscalizar o mercado de saúde suplementar, tendo poderes para regulamentar as relações entre clientes, prestadores de serviço e operadoras.

Para competir nesse mercado, muitas operadoras mudaram sua estratégia de trabalho. Ao invés de contratar serviços terceirizados para o atendimento dos beneficiários, passaram a verticalizar suas estruturas, oferecendo uma rede própria de atendimento (consultórios, pronto-atendimentos, laboratórios, raios- $\mathrm{X}$, hospitais). 0 entendimento era de que com a rede própria a operadora passa a ter autonomia e maior controle sobre seus custos assistenciais, o que não ocorre quando os serviços são realizados pela rede credenciada.

A rede própria de atendimento é interessante tanto para o beneficiário, que dispõe de rede exclusiva para seu atendimento, quanto para a operadora, que visualiza os custos em sua fonte de origem, podendo controlá-los diretamente.

Quando as operadoras possuem rede própria em diversos locais, a gestão descentralizada de custos é um importante instrumento, principalmente para que os custos sejam controlados por unidade de atendimento, possibilitando a análise individualizada da rede própria, em cada ponto de atendimento.

O controle dos custos na operadora é relevante para a sua continuidade neste mercado cada vez mais restritivo e de concorrência acirrada, sendo a gestão de custos um importante instrumento de apoio ao processo decisório. A partir dessa ferramenta, criamse condições para uma gestão mais eficaz, para manter o desenvolvimento sustentável dos negócios.

É nesse contexto que se desenvolve esse estudo, cujo objetivo está direcionado ao desenvolvimento de um sistema de custeio que possibilite fazer a análise comparativa entre os custos de manutenção da rede própria versus o custo de contratar uma rede terceirizada para a prestação de serviços médicos por uma operadora brasileira de planos de saúde.

Tem-se, assim, que a delimitação do estudo está marcada por duas contribuições específicas e complementares: (1) o desenvolvimento de um sistema de mensuração de custos que produza informações mais elaboradas, prática não comum no segmento; (2) apresentação de uma aplicação gerencial dessas informações, no caso a análise comparativa com o custo de serviços terceirizados, suporte necessário a uma possível adoção dessa estratégia. 


\section{REFERENCIAL TEÓRICO}

\subsection{SAÚDE SUPLEMENTAR}

Os serviços de saúde no Brasil podem ser públicos ou privados. 0 atendimento público é realizado através do Sistema Único de Saúde (SUS), com parte da gestão descentralizada para os municípios. Já os serviços privados vão desde o atendimento particular em um consultório médico até o serviço prestado.

A esse respeito, Farias e Melamed (2003) enfatizam que o mercado privado de assistência à saúde traz para o setor a questão da eficiência, enquanto o governo seria responsável por uma distribuição eqüitativa de bens de saúde essenciais.

Segundo Ribeiro (2004), alguns fatores contribuíram para a expansão dos planos de saúde no Brasil. São eles: (1) a falta de investimento público na área da saúde; (2) as empresas passaram a considerar a assistência à saúde como um dos mais importantes benefícios aos seus empregados; (3) a saturação do mercado de trabalho médico, diante do baixo percentual da população capaz de custear diretamente os serviços de que necessita; (4) os custos crescentes dos serviços de saúde, o que reduz o número de pessoas que podem utilizá-los habitualmente mediante pagamento direto; (5) a insatisfação da classe média com a qualidade dos serviços oferecidos pelo SUS, em especial nos aspectos mais valorizados por esses usuários, tais como o conforto, presteza e atendimento personalizado.

Com o objetivo de padronizar a atuação do setor e oferecer proteção ao consumidor, em 1998 foi sancionada a Lei $\mathrm{n}^{\circ}$ 9.656/98 regulamentando os planos de saúde no Brasil. As principais alterações estabelecidas por esta lei foram as seguintes: (1) normas para a constituição de operadoras de planos de saúde; (2) obrigação do registro de produtos comercializados pela operadora, com definição das suas coberturas; (3) estabelecimento de coberturas mínimas obrigatórias para os planos; (4) determinação de regras para períodos de carência de cobertura, doenças preexistentes e aumento de preços.

As operadoras passaram a ter a liberdade de definir como disponibilizar o serviço de saúde aos seus clientes. Algumas operadoras têm rede própria de atendimento, oferecendo em sua estrutura médicos, centros de diagnósticos e até mesmo hospitais. Outras operadoras trabalham apenas com rede credenciada, tendo todos os serviços do plano de saúde terceirizados. Há também a possibilidade de oferecer o serviço de forma mista, ou seja, tanto na rede própria como na rede credenciada.

A opção pela oferta de atendimento a seus beneficiários via estrutura própria ou credenciada, ou mistos, depende da administração da operadora, a qual define os critérios a serem adotados para o produto que comercializa.

A seguir é apresentada a forma como ocorre a disponibilização do serviço em uma operadora que oferece atendimento por meio da rede própria e da rede credenciada: 


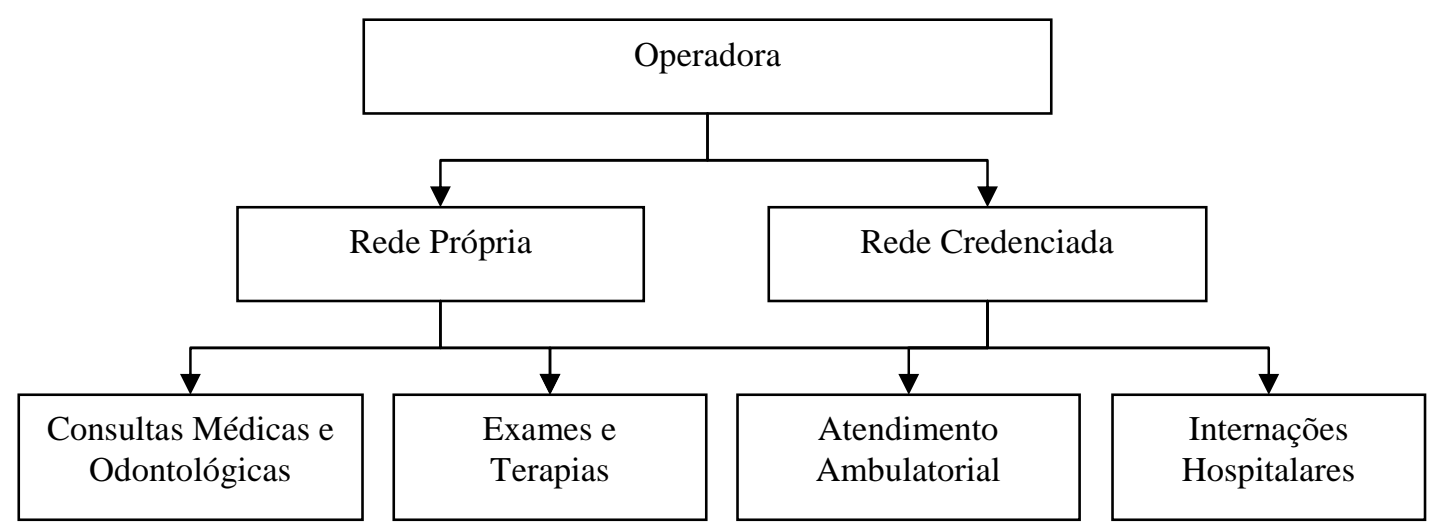

Figura 1 - Estrutura de Atendimento da Operadora

Fonte: Elaborado pela autora

A rede própria da operadora de planos de saúde nada mais é do que a verticalização da prestação de serviços de saúde.

O termo verticalização, de acordo com Alves (2006), caracteriza o processo de integração das atividades de gerenciamento de planos de saúde e prestação direta de serviços médicos em uma única unidade empresarial.

O custo da rede credenciada para a operadora é conhecido, pois seu valor é determinado em contrato. Já na rede própria, o custo tem uma mensuração mais complexa, pois é oferecido dentro de um estabelecimento e com sua estrutura mantida pela operadora.

Segundo Araújo (2006), o controle de custos tornou-se fundamental para o mercado de planos de saúde que, desde a regulamentação, sofreu com aumento dos gastos devido à ampliação obrigatória da cobertura, e ainda com o controle dos reajustes dos planos de pessoa física que é fixado pelo governo federal.

Araújo (2006) acrescenta que há uma tendência das operadoras em investir na rede própria e cita como exemplo a Amil que tem dois hospitais próprios, as cooperativas médicas no Rio Grande do Sul que tem quatro hospitais e a Ulbra Saúde que também tem quatro hospitais próprios.

O ganho da operadora com a verticalização, segundo Alves (2006), está no melhor monitoramento dos atendimentos cobertos pelo plano e no controle dos custos, pois ela detém a logística da utilização dos serviços pelos beneficiários.

A relação entre a operadora e o serviço credenciado, segundo Alves (2006), é marcada por assimetrias informacionais. 0 conflito surge porque o que representa custo para as operadoras, representa receita para os serviços credenciados.

O objetivo do serviço credenciado é realizar o maior número de serviços possíveis para aumentar a sua remuneração, pois recebe por atendimento realizado. Já a operadora tem vantagem quando o beneficiário não utiliza o plano de saúde, pois sua receita é fixa. Nesse caso, quando o beneficiário paga a mensalidade do plano, mas não utiliza nenhum serviço de saúde, a operadora apenas acumula a receita como resultado desse plano. 


\subsection{MENSURAÇÃO E GESTÃO DE CUSTOS}

Atribuir custos aos objetos de custeio é talvez a função mais básica da contabilidade de custos (MARTINS, 2003). Seja custear produtos, linha de produtos, serviços, processos ou outros objetos ou entidades contábeis (centro de custo, divisão, unidade de negócio), tem-se que nessa atividade o objetivo básico é conhecer o quanto de recursos foi consumido.

Nesse sentido, diversos são os métodos disponíveis para a atividade de custeio, cada um deles selecionando quais tipos de custos considerar e qual processo de custeio aplicar.

Para o desenvolvimento desse estudo optou-se pelo uso método de custeio pleno. Tal opção deve-se ao fato de ele considerar a totalidade dos gastos da unidade de atendimento da operadora, sem exceções, resultando em uma informação mais completa que a de outros métodos de custeio, como o variável, por exemplo.

Conforme Vartanian (2000), a aplicação do método de custeio pleno apresenta como vantagem o fato de serem levados em conta todos os gastos ocorridos em uma organização, sem exceções, o que resulta em uma informação de custos completa e conservadora. É essa informação completa dos gastos envolvidos nos serviços que torna possível a comparação com o preço cobrado pela rede credenciada, dado que nesse preço estão considerados todos os gastos incorridos por ela na prestação dos serviços. Portanto, entende-se que o método pleno é aquele que oferece maior poder de comparabilidade entre o custo da rede própria e o preço cobrado pela rede credenciada.

Assim, o custeio pleno, no caso estudado, possibilita a análise da viabilidade de manutenção da rede própria local, pois a estrutura existente é a mínima necessária para o funcionamento da unidade, justificando também o comparativo com a rede credenciada local.

Não obstante, deve-se reconhecer que o método de custeio pleno envolve a alocação por rateio dos custos indiretos e das despesas operacionais. Essa deficiência, presente em qualquer método que faça esse tipo de alocação, pode ser reduzida quanto ao seu impacto na super ou sub-avaliação dos custos objeto de custeio, mediante análise mais cuidadosa na seleção das bases de rateio.

Além da mensuração dos custos, o que se dá pela aplicação de um método de custeio, Pompermayer (1999) observa que para uma empresa ser bem-sucedida na gestão de custos precisa, também, implantar em seu ambiente operacional uma tecnologia de gestão compatível com as suas necessidades gerenciais de controle. Isso é necessário para a avaliação dos resultados dos seus produtos, servindo também como ferramenta de apoio na elaboração do planejamento estratégico da organização.

Com esse mesmo entendimento Bacic (1994) observa que a mensuração e gestão de custos visam à melhoria da gestão dos negócios, mas que isoladamente isso não é suficiente para manter a empresa competitiva. Nesse sentido Bacic (1994) acrescenta que o envolvimento com a estratégia passa a ser relevante, possibilitando uma análise mais profunda para a determinação do posicionamento estratégico da empresa.

A gestão de custos utiliza dados da contabilidade de custos para a tomada de decisão, identificando estratégias que contribuirão para o crescimento dos negócios e para a sobrevivência da empresa no longo prazo, via criação de vantagens competitivas sustentáveis (COSTA; SANTOS; SANTOS, 2006). Nesse enfoque, a empresa mantém sua vantagem competitiva, analisando e implementando ações com base nas informações da contabilidade de custos. 
Tem-se, então, que a contabilidade gerencial de custos atende principalmente à necessidade de informações internas da empresa, porque apresenta o detalhamento necessário para que o gestor a utilize como instrumento para a tomada de decisão.

$\mathrm{Na}$ área da saúde, conforme destaca Felicíssimo (2000), tem-se uma disciplina especialmente voltada à sua gestão econômica, denominada economia da saúde, a qual é essencialmente a aplicação de uma disciplina, a economia, a um conjunto específico de fenômenos convencionalmente relacionados à saúde. Aplica os conceitos e modelos econômicos aos temas relacionados com a saúde, justificando-se teoricamente em função de que neste campo, assim como em outros segmentos da atividade social-empresarial, ocorre uma situação de escassez relativa dos recursos para alcançar fins alternativos, o que exige estabelecimento de escolhas estratégicas e/ou operacionais, via ação de um processo decisório.

A preocupação com o tratamento econômico da área da saúde também é destacada por Gadelha (2003), o qual suporta sua argumentação no movimento recente de revolução tecnológica (com fortes implicações no crescimento dos custos da área da saúde) e no fenômeno da globalização (com suas repercussões no mercado em termos de concorrência acirrada e busca pela eficiência e eficácia empresarial).

A respeito dos avanços tecnológicos, Rezende (2002) destaca que a par dos modernos recursos tecnológicos proporcionarem ao médico todos os meios necessários para um diagnóstico preciso, tanto do ponto de vista topográfico como etiológico e, o que é mais importante, mais precoce, com evidente benefício para os pacientes, aspectos desfavoráveis também merecem destaque. 0 principal deles refere-se ao expressivo aumento dos custos dos procedimentos médicos, dado o investimento realizado, além das despesas decorrentes da possível utilização abusiva da tecnologia médica.

Gadelha (2003) acrescenta que tanto os espaços privados quanto os públicos tem passado por um processo de transformação no modelo de gestão e organização da produção de bens e serviços em saúde na direção de um padrão empresarial, inclusive nos casos em que o objetivo do lucro não se coloca como finalidade primordial, sendo substituído por metas alternativas de desempenho (referidas, por exemplo, à produção, qualidade, custos e compromissos de atendimento de populações ou clientelas específicas).

Matos (2002), com uma abordagem mais específica, destaca que um sistema de gestão de custos aplicado às instituições de saúde assume papel importante na necessidade de viabilizar as organizações de saúde, tanto públicas quanto privadas.

Porter e Teisberg (2004) alertam que minimizar custos em serviços de saúde pode levar a resultados contraproducentes. A economia de custos deve advir de reais eficiências na prestação de serviços e não na restrição de tratamentos ou na redução da qualidade dos mesmos.

Miranda (2003) destaca que um complicador do gerenciamento de custos das operadoras de planos de saúde está, sobretudo, num regime onde as receitas são fixas e pré-determinadas e os gastos com assistência à saúde são variáveis.

Assim, a operadora recebe mensalmente uma receita, conhecida desde que comercializou o plano, mas desconhece o custo que o plano pode gerar, não sendo possível avaliar a margem a ser obtida com o plano, que varia em função da utilização do beneficiário.

Com a utilização da rede própria, a operadora neutraliza a ação dos credenciados na realização de serviços desnecessários no atendimento aos beneficiários. Em sendo assim, a operadora passa a ter o controle direto sobre os serviços realizados aos beneficiários do seu plano de saúde. 


\subsection{DESCENTRALIZAÇÃO}

Descentralização, segundo Hansen e Mowen (2001), é a prática de delegar autoridade de tomada de decisão para níveis inferiores de responsabilidade. Ocorre normalmente quando as empresas possuem filiais ou unidades de produção que operam separadamente. A gestão de custos descentralizada auxilia no processo de tomada de decisão, facilitando a análise individualizada dos custos.

Para Gomes e Salas (1999), antes de a empresa decidir pela descentralização, deverá definir claramente o poder de decisão que se transfere a cada responsável de área.

Warren, Reeve e Fess (2001) acrescentam ainda que o grau adequado de descentralização depende muito das características da empresa, pois existem negócios em que os gerentes de divisão têm autoridade sobre todas as operações da unidade e em outras apenas sobre parte delas.

A descentralização é aplicada nas operadoras de planos de saúde, quando estas possuem mais de uma unidade de atendimento. Com a descentralização, os custos são identificados por unidades individuais, possibilitando um melhor controle para a operadora. Nesses casos, não há transferência de serviços entre as unidades, já que o atendimento é realizado diretamente ao beneficiário na unidade local. Tal aspecto da descentralização dos custos por unidades organizacionais, como aqui destacado, facilita em muito a realização de análises que visam dar suporte à gestão econômica das organizações. É o caso da possível contratação de serviços de rede credenciada em substituição ao uso de rede própria.

De outro modo, se a operadora não utiliza controles descentralizados, as informações são apenas em nível geral, o que limita muito a gestão das unidades de atendimento. Além disso, na gestão descentralizada, o gerente pode analisar e avaliar o desempenho da sua unidade dentro da organização, sendo esse um fator de incentivo para a unidade aumentar sua participação no resultado geral da operadora. Cabe observar que a maior participação pode se dar pela contratação de rede credenciada, objeto deste estudo, decisão essa avaliada via mensuração e análise dos custos envolvidos em contraposição ao valor cobrado por um credenciamento externo.

\section{ASPECTOS METODOLÓGICOS}

\subsection{CLASSIFICAÇÃO DA PESQUISA}

O procedimento técnico utilizado nesta pesquisa é o estudo de caso, desenvolvido em uma operadora de planos de saúde com o objetivo de desenvolver uma forma de mensuração do custo por tipo de atendimento na rede própria da operadora e usá-lo como ferramenta para sustentação da decisão estratégica da empresa.

Quanto aos objetivos a pesquisa é classificada como descritiva, de abordagem qualitativa. Corroborando tal classificação, Gil (1999) destaca que o estudo de caso também pode ser utilizado em pesquisas descritivas.

Por tratar-se de um estudo de caso único, e dado o objetivo da pesquisa, as fontes de evidências circunscrevem-se ao sistema de informações contábeis e operacionais da entidade objeto do estudo, de análise documental complementar e dos preços cobrados pela rede terceirizada. Além disso, utilizou-se também de informações complementares obtidas em entrevista com o principal gestor operacional da operadora. Ao final, as 
variáveis trabalhadas correspondem ao custo interno da operadora, analisado em relação ao preço da rede credenciada.

Os dados de custos utilizados são de uma unidade de atendimento específica da operadora, localizada na cidade de São Leopoldo (RS), ou seja, são dados descentralizados da empresa. Optou-se pela utilização de dados descentralizados porque as unidades oferecem diferentes tipos de serviços aos beneficiários, e possuem estruturas físicas diferentes para a prestação de serviço, sendo a unidade de São Leopoldo uma das mais completas em relação a tipos de atendimentos.

\subsection{PROCEDIMENTOS TÉCNICOS PARA O CUSTEIO}

Para a mensuração de custos foram definidos alguns critérios. São eles:

a) o objeto de custeio na rede própria é o tipo de atendimento. Por tipo de atendimento entendem-se os serviços oferecidos aos beneficiários dos planos de saúde dentro da estrutura própria da operadora;

b) identificação dos tipos de serviços oferecidos na unidade própria da operadora: avaliar a relação de todos os atendimentos feitos pela rede própria da operadora na cidade de São Leopoldo, durante o ano de 2006;

c) os serviços foram segmentados em consultas médicas, ambulatório, odontologia e exames, sendo custeado cada um dos atendimentos dentro dos grupos. A exceção é quanto ao ambulatório, que por abranger uma grande variedade de serviços foi considerado em seu conjunto;

d) classificação dos custos da rede própria: os custos são identificados e classificados em diretos e indiretos, fixos e variáveis;

e) para cálculo dos custos da rede própria foi utilizado o método de custeio pleno. Objetiva-se trabalhar com bases de alocação mais refinadas, em contraposição às críticas a este método. Para isso os custos indiretos foram analisados individualmente, com vistas a identificar a melhor forma de apropriá-los aos objetos de custeio. Procurou-se, assim, reduzir o impacto das possíveis distorções de custeio reconhecidas na seção 2.2.

Após a identificação do custo do atendimento, iniciou-se o trabalho de comparação com a rede credenciada. Esse comparativo foi efetuado da seguinte forma:

a) levantamento de todos os contratos com a rede credenciada da cidade de São Leopoldo para identificação dos preços cobrados para os serviços;

b) para os serviços oferecidos na rede própria, mas que não estão disponíveis na rede credenciada de São Leopoldo, foi adotado o preço do serviço na rede credenciada da cidade mais próxima;

c) para a odontologia foi utilizada a tabela da Odontoprev, pois a operadora não tem contrato com rede credenciada para atendimento odontológico;

d) elaboração de um quadro comparativo de preços, considerando quanto custa o serviço na rede própria e quanto custa na rede credenciada. Com esse comparativo é possível identificar quais os serviços de menor custo na rede própria, estabelecendo a vantagem da operadora em manter o serviço próprio.

A comparação dos custos apurados na rede própria com os custos da rede credenciada tem como objetivo evidenciar a vantagem ou desvantagem da operadora em ter uma rede própria. Esse comparativo possibilita decisões de caráter estratégico para a empresa. 


\section{APRESENTAÇÃO E ANÁLISE DOS DADOS}

\subsection{A OPERADORA OBJETO DA ANÁLISE}

A operadora foi fundada em 1996, antes da regulamentação governamental do setor de planos de saúde. É uma operadora da modalidade de Medicina de Grupo, constituída como sociedade limitada, de acordo com o código civil de 2002.

A operadora comercializa planos coletivos e familiares com cobertura ambulatorial, odontológica, hospitalar e suas combinações. A atuação da operadora é de âmbito regional, atendendo a beneficiários em uma região do Rio Grande do Sul.

A maior concentração de beneficiários da operadora está nos planos coletivos com cobertura ambulatorial mais odontológica, correspondente a $72 \%$ do total de sua carteira. Os planos coletivos (planos firmados com pessoas jurídicas) representam $90 \%$ do total de beneficiários da operadora, conforme visualizado no Gráfico 1:

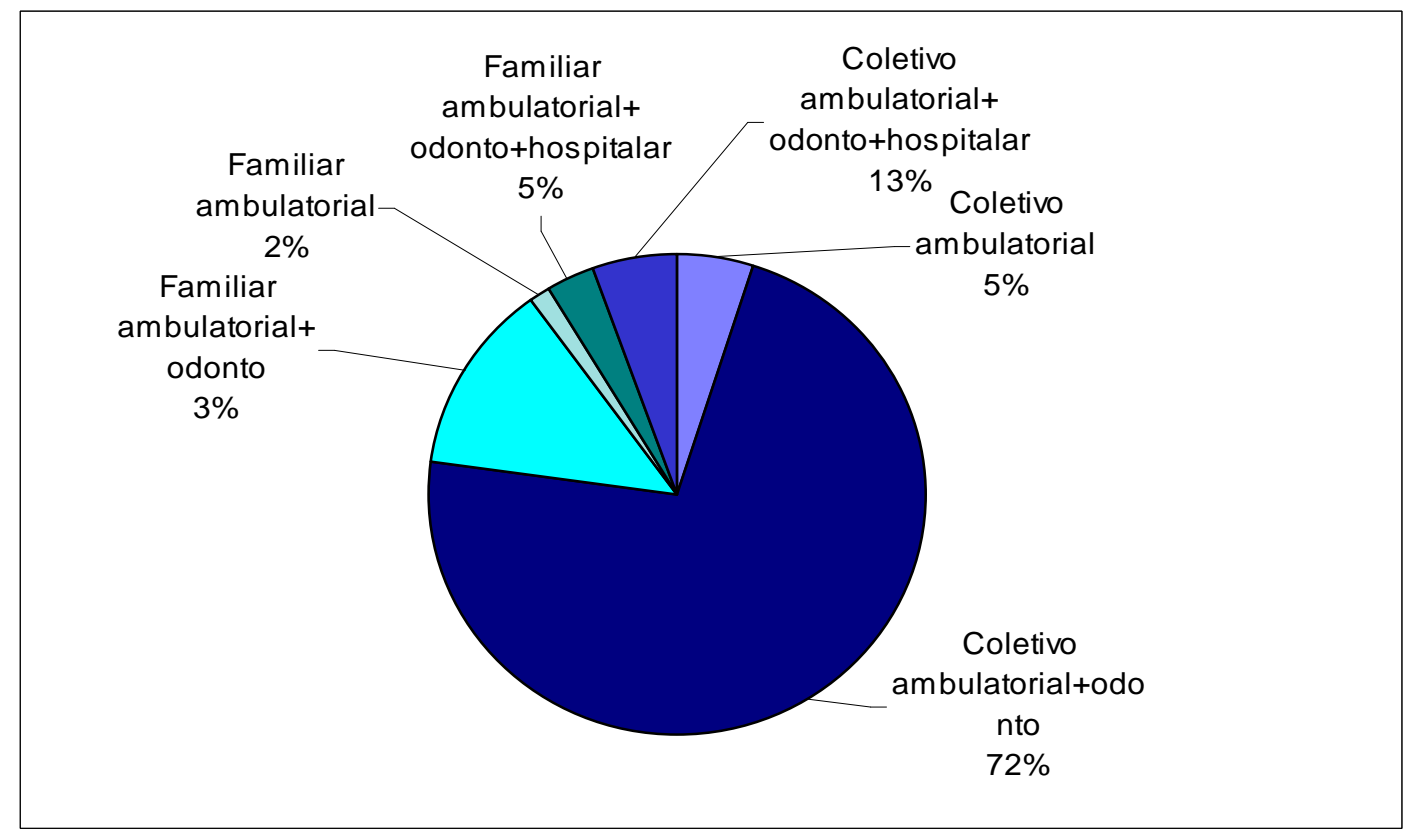

Gráfico 1 - Planos Comercializados pela Operadora

Fonte: Elaborado pela autora com base nos dados do Sistema ERP da Operadora.

Com a regulamentação dos planos de saúde em 1999, a operadora registrou seus planos na ANS, e passou a comercializar somente os planos aprovados por esta agência, conforme determinado pela legislação. Também em 1999 a empresa conseguiu registro provisório de operadora junto a ANS e, em 2006, passou a ter o seu registro definitivo.

A gestão das unidades de atendimento é descentralizada, havendo um gerente para cada filial, com poder de decisão local. A autonomia dos gerentes é de caráter administrativo, tendo poderes para substituição de pessoal, decisões sobre as necessidades de manutenção e compra de alguns materiais.

De acordo com a classificação da ANS, a operadora é considerada de médio porte, por estar na faixa de 20.000 a 100.000 beneficiários, de acordo com a RN 27/03 (ANS, 2003). Em 2007, a carteira era composta por 43.000 beneficiários. Essa carteira de beneficiários gera um faturamento mensal em torno de R\$ 2 milhões. Em 2006, o 
faturamento anual atingiu R\$ 20 milhões, representando um crescimento de $11 \%$, se comparado ao ano de 2005, cujo faturamento foi de R\$ 18 milhões.

A empresa conta com um quadro funcional de 340 pessoas, dividido entre as oito filiais que compõem a entidade. Dentre os funcionários estão os profissionais médicos e odontologistas que atendem na rede própria da operadora.

$\mathrm{Na}$ maioria dos planos comercializados pela operadora o primeiro atendimento ao beneficiário ocorre na rede própria pelo clínico geral, pediatra ou ginecologista, que faz uma triagem para posterior encaminhamento a especialistas. 0 encaminhamento à rede credenciada ocorre mediante autorização da operadora e somente quando não há disponibilidade para a realização do serviço na rede própria.

O acompanhamento do desempenho das unidades é feito por meio de indicadores não-financeiros e controles qualitativos, como índice de demora no atendimento ao cliente, tempo de espera para agendamento de consultas, satisfação do cliente pelo atendimento realizado. 0 controle financeiro é realizado apenas por meio das informações contábeis da operadora como um todo.

A unidade de atendimento selecionada para o estudo é a situada na cidade de São Leopoldo (RS), é a que apresenta a melhor estrutura física da operadora na região do Vale dos Sinos. É a única unidade que atende 24 horas por dia e dispõe dos principais serviços que a operadora oferece em sua rede própria.

Seu faturamento representa $24 \%$ da totalidade da operadora, e possui $20 \%$ da carteira de beneficiários. A filial dispõe de 60 funcionários, equivalente a $18 \%$ do total de funcionários da operadora. 
A estrutura da unidade é apresentada na Figura 2:

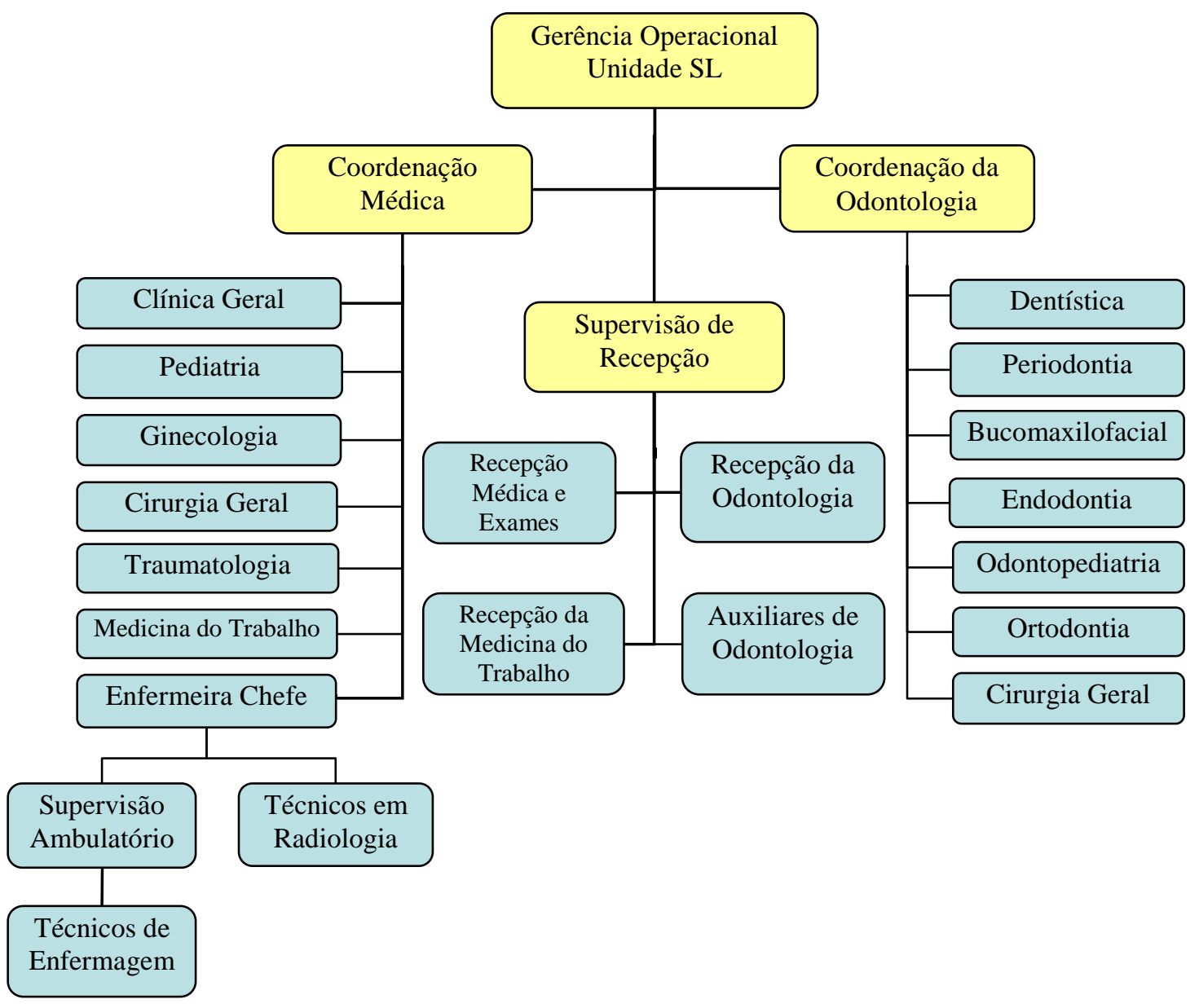

Figura 2 - Organograma da Unidade de São Leopoldo

Fonte: a autora com base em informações internas da operadora.

A unidade apresenta como cargo mais elevado na estrutura organizacional a gerência operacional, responsável por todas as decisões de caráter operacional da clínica.

As coordenações médica e odontológica tratam diretamente com os médicos e odontologistas, e são os responsáveis clínicos pelos atendimentos efetuados, respondendo, respectivamente, por toda a equipe médica e odontológica da unidade.

Fica a cargo da enfermeira-chefe a supervisão dos técnicos de enfermagem e dos técnicos em radiologia.

A supervisão da recepção é responsável pelos recepcionistas da unidade, independentemente da área a que se referem (consultas, exames, odontologia).

\subsection{ELABORAÇÃO DO SISTEMA DE CUSTOS}

O sistema de custos foi elaborado em planilha eletrônica no programa MS-Excel. Os dados de custos, do número de atendimentos e da agenda de atendimentos da unidade foram cedidos pela operadora estudada e foram coletados dos relatórios do sistema operacional (Enterprise Resource Planning - ERP). No final do ano de 2006, a operadora 
iniciou a implantação de um novo sistema operacional, com o objetivo de integrar todas as áreas da empresa, visando melhorar a qualidade do banco de informações.

No mesmo período, a operadora fez uma reestruturação no modo de operação da sua rede própria. Essa reestruturação modificou a forma de contratação dos profissionais, que passaram de mão-de-obra terceirizada para mão-de-obra com vínculo empregatício. Devido a isso, foi descartada a possibilidade de utilizar dados do ano de 2006, pois os gastos com a rede própria da operadora foram profundamente modificados nesse período.

O período cedido pela operadora para os testes do sistema é referente ao primeiro trimestre de 2007. Os dados posteriores a esse período não estão disponíveis devido à citada implantação do novo sistema operacional, que passou a operar a partir do mês de maio de 2007, havendo ainda a necessidade de ajustes para seu correto funcionamento.

No sistema elaborado, os tipos de atendimento são apresentados nas colunas da planilha, com as seguintes divisões:

\begin{tabular}{|c|c|}
\hline Atendimentos na Rede Própria & Serviços Custeados \\
\hline Consultas Médicas & $\begin{array}{c}\text { Clínica Geral } \\
\text { Pediatria } \\
\text { Ginecologia } \\
\text { Medicina do trabalho } \\
\text { Cirurgia geral } \\
\text { Traumatologia } \\
\end{array}$ \\
\hline Ambulatório & Atendimentos enfermagem \\
\hline Odontologia & $\begin{array}{c}\text { Dentística } \\
\text { Endodontia } \\
\text { Periodontia } \\
\text { Odontologia em saúde coletiva } \\
\text { Bucomaxilofacial } \\
\text { Técnico em higiene dental } \\
\text { Odontopediatria } \\
\end{array}$ \\
\hline Exames & $\begin{array}{c}\text { Raio-X } \\
\text { Ecografia } \\
\text { Mamografia } \\
\text { Eletrocardiograma } \\
\text { Colonoscopia } \\
\text { Endoscopia } \\
\text { Audiometria } \\
\text { Eletroencefalograma } \\
\text { Espirometria }\end{array}$ \\
\hline
\end{tabular}

Quadro 1 - Serviços Custeados no Sistema de Custos

Fonte: Dados do Sistema ERP da Operadora.

O Quadro 1 apresenta a segmentação de todos os serviços que estão custeados no sistema elaborado neste estudo. Após essa segmentação foram analisados, com base no balancete contábil, os custos da filial da operadora. O objetivo dessa etapa foi fazer a divisão entre custos diretos e indiretos para estruturação do sistema de custeio.

A classificação dos custos entre diretos e indiretos, fixos e variáveis, foi feita em relação ao tipo de atendimento, sendo analisado o processo interno da operadora. Depois de efetuada a classificação, as informações foram apresentadas para a gerente da unidade e para o diretor administrativo, que confirmaram a forma de comportamento dos custos. 
Os custos diretos foram atribuídos especificamente aos atendimentos. Já os custos indiretos foram atribuídos por rateio, de acordo com critérios considerados mais adequados para este estudo, apresentados no desenvolvimento do sistema.

A seguir, no Quadro 2, apresenta-se a relação dos custos da filial, com a classificação entre custos diretos e indiretos, fixos e variáveis:

\begin{tabular}{|c|c|c|}
\hline Relação dos Custos & \multicolumn{2}{|c|}{ Classificação } \\
\hline Água & Indireto & Fixo \\
\hline Aluguel & Indireto & Fixo \\
\hline Coleta de Lixo Hospitalar & Direto & Variável \\
\hline Depreciação/Amortização & Indireto & Fixo \\
\hline Energia Elétrica & Indireto & Fixo \\
\hline Estagiários & Indireto & Fixo \\
\hline IPTU & Indireto & Fixo \\
\hline Manutenção e Conservação & Indireto & Fixo \\
\hline Material de Consumo Exames Filmes & Indireto & Variável \\
\hline Material de Consumo Médico/Medicamentos Ambulatório & Direto & Variável \\
\hline Material de Consumo Odontologia & Indireto & Variável \\
\hline Material de Expediente & Indireto & Variável \\
\hline Material de Limpeza & Indireto & Fixo \\
\hline Rouparia/Lavanderia & Direto & Variável \\
\hline Salários e Encargos Coordenador da Recepção & Indireto & Fixo \\
\hline Salários e Encargos Enfermagem & Direto & Fixo \\
\hline Salários e Encargos Gerência e Coord. Médica/Odonto & Indireto & Fixo \\
\hline Salários e Encargos Médicos/Odontologistas & Direto & Fixo \\
\hline Salários e Encargos Recepção Medicina do Trabalho & Direto & Fixo \\
\hline Salários e Encargos Recepção Médica/Exames & Indireto & Fixo \\
\hline Salários e Encargos Recepção Odontologia & Indireto & Fixo \\
\hline Salários e Encargos Serviços de Limpeza & Indireto & Fixo \\
\hline Salários e Encargos Técnico Radiologia & Indireto & Fixo \\
\hline Seguro & Indireto & Fixo \\
\hline Serviços Terceirizados Exames & Direto & Variável \\
\hline Serviços Terceirizados Médicos & Direto & Variável \\
\hline Telefone & Indireto & Fixo \\
\hline Vigilância & Indireto & Fixo \\
\hline
\end{tabular}

Quadro 2 - Composição e Classificação dos Custos

Fonte: Balancete da Operadora estudada.

A maioria dos custos é indireto e fixo, na proporção de $71 \%$ do custo total. Devido a essa proporção, não se justifica a utilização do método de custeio variável para cálculo do custo da unidade, principalmente para decisões estratégicas e de efeito a longo prazo, pois o custo variável representa apenas uma pequena parte dos custos totais da estrutura de atendimento. Esse entendimento é referendado por Horngren, Foster e Datar (2000), os quais argumentam que é justificável a alocação dos custos indiretos devido ao fato deles representarem considerável proporção dos custos totais atribuídos aos objetos de custeio.

Dado não haver divisão entre tipos de atendimentos ambulatoriais, todos os gastos com o ambulatório foram considerados diretos. Para os outros atendimentos os custos considerados como diretos são os seguintes: 
a) Coleta de Lixo Hospitalar: Os resíduos hospitalares, como seringas, agulhas, só podem ser coletados por empresa especializada. Esse custo é registrado diretamente no ambulatório, pois é o local onde são gerados.

b) Material de Consumo Médico/Medicamentos do Ambulatório: Esses materiais são consumidos somente no ambulatório, nos atendimentos de enfermagem, por isso são considerados diretos.

c) Rouparia/Lavanderia: a rouparia é trocada a cada realização de procedimentos, que ocorre na enfermagem, sendo apropriado diretamente aos atendimentos do ambulatório.

d) Salários e Encargos Enfermagem: 0 técnico de enfermagem atende apenas no ambulatório, onde é apropriado seu salário.

e) Salários e Encargos Médicos/Odontologistas: Cada especialista realiza um tipo de atendimento. Dessa forma os salários são apropriados dentro do tipo de atendimento que eles realizam.

f) Salários e Encargos Recepção Medicina do Trabalho: A medicina do trabalho tem uma recepcionista exclusiva, sendo possível considerar seu salário diretamente ao atendimento da especialidade.

g) Serviços Terceirizados Exames: Cada serviço terceirizado realiza um tipo de exame, sendo apropriado diretamente ao exame contratado com o serviço.

h) Serviços Terceirizados Médicos: Os médicos terceirizados estão apropriados diretamente à especialidade que atendem.

Os demais custos listados no Quadro 2 foram considerados indiretos, pois vários tipos de atendimento usufruem os mesmos recursos. É devido a isso que esses custos são apropriados por meio de rateio. 
As bases de rateio selecionadas são as seguintes:

\begin{tabular}{|c|c|c|}
\hline Critério & $\begin{array}{l}\text { Aplicação ao Tipo } \\
\text { de Atendimento }\end{array}$ & $\begin{array}{c}\text { Custos vinculados ao tipo de } \\
\text { Atendimento }\end{array}$ \\
\hline \multirow{9}{*}{$\begin{array}{l}\text { Número de } \\
\text { Atendimentos }\end{array}$} & Atendimentos da Odontologia & Materiais de consumo odontológicos \\
\hline & $\begin{array}{c}\text { Atendimentos de Raios-X, ecografia e } \\
\text { mamografia }\end{array}$ & Material de consumo exames \\
\hline & Total de atendimentos da unidade & Material de expediente \\
\hline & $\begin{array}{l}\text { Total de atendimentos da unidade menos o } \\
\text { ambulatório }\end{array}$ & Remuneração de Estagiários \\
\hline & $\begin{array}{l}\text { Total de atendimentos da unidade menos o } \\
\text { ambulatório }\end{array}$ & $\begin{array}{l}\text { Salário e encargos coordenação da } \\
\text { recepção }\end{array}$ \\
\hline & Atendimentos médicos e de exames & $\begin{array}{l}\text { Salário e encargos recepção médica } \\
\text { e exames }\end{array}$ \\
\hline & Atendimentos de Raios-X e mamografia & $\begin{array}{c}\text { Salário e encargos técnicos em } \\
\text { radiologia }\end{array}$ \\
\hline & Total de atendimentos da unidade & $\begin{array}{c}\text { Salários e encargos da gerência da } \\
\text { unidade }\end{array}$ \\
\hline & Atendimentos da Odontologia & $\begin{array}{c}\text { Salários e encargos da recepção da } \\
\text { odontologia }\end{array}$ \\
\hline \multirow{9}{*}{ Área Física } & \multirow{9}{*}{ Área física total da unidade } & Água \\
\hline & & Aluguel \\
\hline & & Depreciação/Amortização \\
\hline & & IPTU \\
\hline & & Manutenção e Conservação \\
\hline & & Material de limpeza \\
\hline & & Salários e encargos higienização \\
\hline & & Seguro \\
\hline & & Vigilância \\
\hline KW Instalado & Equipamentos e lâmpadas por área & Energia elétrica \\
\hline Número de Ramais & Ramais por área & Telefone \\
\hline
\end{tabular}

Quadro 3 - Critérios de Alocação dos Custos Indiretos

O critério "Número de Atendimentos" foi utilizado para apropriação dos custos com as áreas envolvidas diretamente com os atendimentos, que tem o volume de trabalho afetado pela sua quantidade, e também para os custos que variam em função dos atendimentos que a unidade realiza. A apropriação segue a proporção específica do atendimento desenvolvido, apresentado no Quadro 3.

O critério "Área Física” foi utilizado para os custos que estão relacionados com o espaço da unidade de atendimento. O consumo de água ocorre pela higienização do local, sendo mais bem distribuído pela área da unidade, assim como a remuneração para o pessoal da higienização e o material de limpeza. A área física também é considerada para a apropriação do aluguel, IPTU e da manutenção e conservação de prédios. Ainda relacionados à área física estão o seguro predial e a vigilância através de sistema eletrônico.

Quanto à depreciação/amortização, como a empresa não tem controle patrimonial dos bens imobilizados por filial, esse valor refere-se ao gasto com a reforma do prédio para adequar as instalações às necessidades de atendimento da unidade, apropriado conforme o prazo do contrato de aluguel. Por isso, também foi utilizado o critério "área física" para este gasto. Conforme informações do gestor operacional, esse critério não causa impactos 
relevantes na mensuração dos custos, visto que os procedimentos médicos que exigem estruturas mais avançadas (p. ex. centro cirúrgico e laboratórios clínicos de maior complexidade) e consequentemente maiores investimentos em tecnologia, já são feitos em instalações terceirizadas. Baseado nessas mesmas informações, identificou-se que o valor da depreciação/amortização assumido no estudo é considerado suficiente para expressar o custo dos outros investimentos realizados pela operadora em tecnologia.

O critério "kw Instalado" foi utilizado para o consumo de energia, considerando o número de equipamentos e lâmpadas existentes em cada área de atendimento da unidade. área.

O critério "Número de Ramais" foi utilizado para definir o custo com telefone por

Definidos esses critérios, a planilha foi alimentada com os dados provenientes de diversas fontes, obtidas com a operadora, conforme exposto a seguir:

a) Folha de pagamento: Os custos foram divididos por área de trabalho, para que pudessem ser apropriados aos atendimentos que prestam serviço. A folha foi dividida entre custos diretos e indiretos, de acordo com a classificação mencionada no Quadro 2.

b) Relação de encargos incidentes sobre a folha de pagamento: Assim como a remuneração, os encargos (INSS, FGTS, Insalubridade) foram segmentados por área de trabalho, considerando a mesma divisão aplicada à folha de pagamento.

c) Relatório de benefícios concedidos (vale transporte e vale refeição): Foram considerados juntamente com a remuneração da folha de pagamento, por área de trabalho, sendo apropriado juntamente com a folha de pagamento da área.

d) Relatório de remuneração de serviços terceirizados (médicos e exames): Os valores pagos aos terceirizados foram segmentados de acordo com o tipo de atendimento realizado por eles na unidade de São Leopoldo.

e) Relatórios de consumo de estoque: 0 consumo foi dividido por tipo de estoque para que fosse apropriado de forma correta aos atendimentos por área específica. 0 relatório apresentou separadamente o consumo do ambulatório, da odontologia e dos exames.

f) Balancete contábil: Através do balancete são identificados os gastos relativos à unidade de São Leopoldo, apresentados no Quadro 2.

g) Estatística de atendimentos realizados: Todos os atendimentos realizados pela unidade de São Leopoldo foram quantificados para que fosse possível apurar o custo unitário do atendimento. Os atendimentos foram segmentados conforme apresentados no Quadro 1.

h) Horários de agenda de atendimentos: Para que fosse possível analisar a ocupação da unidade, foi utilizada a informação da quantidade de horários possíveis de agendamento. Por exemplo, se o profissional médico está disponível para atendimento por três horas diárias, ele pode atender nesse período em torno de doze consultas, considerando uma estimativa de 15 minutos por consulta. Essa informação de doze consultas é apresentada juntamente com a quantidade de consultas realizadas, possibilitando o cálculo da ociosidade de agenda. Essa informação é apresentada nas consultas médicas e nos atendimentos odontológicos.

Os custos, depois de apropriados aos atendimentos, apresentam o valor total por tipo de atendimento. Utiliza-se o total deste custo para apurar o custo unitário de cada atendimento, dividindo o montante pelo total de atendimentos realizados. 
Nas consultas e nos atendimentos da odontologia também é possível analisar a ociosidade das agendas de atendimento, sendo apresentado, logo abaixo da informação do número de atendimentos realizados, o número de atendimentos possíveis de acordo com a agenda.

Com o número de consultas possíveis e realizadas é analisada a ociosidade da agenda de atendimentos, que pode ser ocasionada por horários de baixo fluxo de pessoas na unidade, principalmente no horário noturno.

A seguir são apresentadas as tabelas com os resultados dos cálculos dos custos envolvidos. As tabelas estão divididas por consultas médicas, atendimentos em ambulatório, odontologia e exames. 

Tabela 1 - Apuração do Custo das Consultas Médicas e do Ambulatório

\begin{tabular}{|c|c|c|c|c|c|c|c|c|c|c|}
\hline & & & & & CONSULTAS & MEDICAS & & & TOTAL DO & $\overline{\text { AMBULATÓRIO }}$ \\
\hline RELAÇÃO DE CUSTOS & Valores em R\$ & Base de Rateio & Clinica Geral & Pediatria & Ginecologia & $\begin{array}{c}\text { Medicina do } \\
\text { Trabalho } \\
\end{array}$ & $\begin{array}{c}\text { Cirurgia } \\
\text { Geral }\end{array}$ & $\begin{array}{l}\text { Ortopedia/ } \\
\text { Traumato }\end{array}$ & $\begin{array}{l}\text { CUSTO DAS } \\
\text { CONSULTAS }\end{array}$ & $\begin{array}{l}\text { Atendimentos } \\
\text { Enfermagem }\end{array}$ \\
\hline CUSTOS DIRETOS & & & & & & & & & & \\
\hline $\begin{array}{l}\text { Salários e Encargos Médicos/Odonto } \\
\text { Salários e Encargos Recepcão Med.Trab. }\end{array}$ & & & $58.737,32$ & $19.472,88$ & $9.564,58$ & $\begin{array}{r}18.695,02 \\
6.420,55\end{array}$ & & & $\begin{array}{r}106.469,80 \\
6.420,55\end{array}$ & \\
\hline Serviços Terceirizados Médicos & & & $72.432,00$ & $26.470,00$ & $3.960,00$ & $2.996,00$ & $1.372,25$ & $8.526,00$ & $115.756,25$ & $1.686,10$ \\
\hline Salários e Encargos Enfermagem & & & & & & & & & & $15.682,71$ \\
\hline Coleta de Lixo Hospitalar & & & & & & & & & & 414,00 \\
\hline $\begin{array}{l}\text { Rouparia/Lavanderia } \\
\text { Mat.Consumo Médico/Medicam. Ambul. }\end{array}$ & & & & & & & & & & $\begin{array}{r}900,00 \\
6.215,34\end{array}$ \\
\hline $\begin{array}{l}\text { Mat.Consumo Médico/Medicam. Ambul. } \\
\text { CUSTOS INDIRETOS }\end{array}$ & & & & & & & & & & $6.215,34$ \\
\hline $\begin{array}{l}\text { CUSTOS INDIRETOS } \\
\text { Sárínse }\end{array}$ & & & & & & & & & & \\
\hline Salários e Encargos Recepção Méd/Exames & $37.168,78$ & n.atendimentos & $16.288,62$ & $3.036,58$ & $4.545,70$ & & 265,88 & $2.106,90$ & $26.243,69$ & \\
\hline Salários e Encargos Coord.recepção & $8.330,36$ & n.atendimentos & $2.551,24$ & 475,61 & 711,98 & 468,72 & 41,64 & 330,00 & $4.579,18$ & \\
\hline Estagiários & $2.436,63$ & n.atendimentos & 746,24 & 139,12 & 208,25 & 137,10 & 12,18 & 96,52 & $1.339,41$ & \\
\hline Salários e Enc.Gerência, Coord.med/odonto & $18.656,63$ & n.atendimentos & $4.571,90$ & 852,31 & $1.275,89$ & 839,96 & 74,63 & 591,37 & $8.206,06$ & $3.728,34$ \\
\hline Material de Expediente & $7.105,77$ & n.atendimentos & $1.741,30$ & 324,62 & 485,95 & 319,92 & 28,42 & 225,23 & $3.125,45$ & $1.420,02$ \\
\hline & & N.Atendimentos & 8.883 & 1.656 & 2.479 & 1.632 & 145 & 1.149 & 15.944 & 7.244 \\
\hline & & $\%$ & $24,51 \%$ & $4,57 \%$ & $6,84 \%$ & $4,50 \%$ & $0,40 \%$ & $3,17 \%$ & $43,98 \%$ & $19,98 \%$ \\
\hline Salários e Encargos Serv.Limpeza & $8.212,25$ & área & 982,79 & 862,98 & 730,20 & 373,17 & 90,60 & 281,70 & $3.321,45$ & $1.933,88$ \\
\hline Aluguel & $18.540,33$ & área & $2.218,79$ & $1.948,30$ & $1.648,53$ & 842,49 & 204,55 & 635,99 & $7.498,65$ & $4.366,00$ \\
\hline Manutenção e Conservação & $12.031,40$ & área & $1.439,84$ & $1.264,31$ & $1.069,78$ & 546,72 & 132,74 & 412,71 & $4.866,11$ & $2.833,24$ \\
\hline Seguro & 150,36 & área & 17,99 & 15,80 & 13,37 & 6,83 & 1,66 & 5,16 & 60,81 & 35,41 \\
\hline Vigilância & 587,31 & área & 70,29 & 61,72 & 52,22 & 26,69 & 6,48 & 20,15 & 237,54 & 138,30 \\
\hline Material de Limpeza & $3.149,38$ & área & 376,90 & 330,95 & 280,03 & 143,11 & 34,75 & 108,03 & $1.273,77$ & 741,64 \\
\hline IPTU & $1.360,27$ & área & 162,79 & 142,94 & 120,95 & 61,81 & 15,01 & 46,66 & 550,16 & 320,33 \\
\hline Água & 350,28 & área & 41,92 & 36,81 & 31,15 & 15,92 & 3,86 & 12,02 & 141,67 & 82,49 \\
\hline Depreciação/Amortiz & $17.359,27$ & área & $2.077,45$ & $1.824,19$ & $1.543,52$ & 788,82 & 191,52 & 595,47 & $7.020,97$ & $4.087,88$ \\
\hline & & Área & 51,15 & 44,91 & 38,00 & 19,42 & 4,72 & 14,66 & 172,85 & 100,64 \\
\hline & & $\%$ & $11,97 \%$ & $10,51 \%$ & $8,89 \%$ & $4,54 \%$ & $1,10 \%$ & $3,43 \%$ & $40,45 \%$ & $23,55 \%$ \\
\hline Energia Elétrica & $16.943,22$ & Kw instalado & $1.417,57$ & $1.417,57$ & 489,38 & 763,64 & 380,53 & 380,53 & $4.849,21$ & $3.577,34$ \\
\hline & & Kw instalado & 248,10 & 248,10 & 85,65 & 133,65 & 66,60 & 66,60 & 848,70 & 626,10 \\
\hline & & & $8,37 \%$ & $8,37 \%$ & $2,89 \%$ & $4,51 \%$ & $2,25 \%$ & $2,25 \%$ & $28,62 \%$ & $21,11 \%$ \\
\hline Telefone & $3.196,73$ & setores c/linha & 266,39 & 266,39 & - & 266,39 & 266,39 & 266,39 & $1.331,97$ & 266,39 \\
\hline & & Setores c/ramal & 1,00 & 1,00 & & 1,00 & 1,00 & 1,00 & 5,00 & 1,00 \\
\hline & & $\%$ & $8,33 \%$ & $8,33 \%$ & $0,00 \%$ & $8,33 \%$ & $8,33 \%$ & $8,33 \%$ & $41,67 \%$ & $8,33 \%$ \\
\hline SOMA & $155.578,97$ & & $166.141,34$ & $58.943,09$ & $26.731,48$ & $33.712,84$ & $3.123,10$ & $14.640,84$ & $303.292,69$ & $48.429,40$ \\
\hline Número de Consultas $\mathrm{Pc}$ & & & 8.914 & 3.961 & 2.528 & 2.369 & 183 & 1.175 & 19.130 & \\
\hline Número de Consultas Realizadas & & & 8.883 & 1.656 & 2.479 & 1.632 & 145 & 1.149 & 15.944 & 7.244 \\
\hline$\%$ Ociosidade & & & $0,3 \%$ & $58,2 \%$ & $1,9 \%$ & $31,1 \%$ & $20,8 \%$ & $2,2 \%$ & $114,6 \%$ & \\
\hline Custo da Consulta Possível & & & 18,64 & 14,88 & 10,57 & 14,23 & 17,07 & 12,46 & - & \\
\hline Custo da Consulta Realizadas & & & 18,70 & 35,59 & 10,78 & 20,66 & 21,54 & 12,74 & - & 6,69 \\
\hline
\end{tabular}

Fonte: Elaborado pela autora com base em dados do Sistema ERP da Operadora 
Tabela 2 - Apuração do Custo da Odontologia

\begin{tabular}{|c|c|c|c|c|c|c|c|c|c|c|}
\hline & & & & & & ŌONTOLOC & ज्ञाA & & & \\
\hline RELAÇÃO DE CUSTOS & Valores em R\$ & Base de Rateio & Dentística & Endodontia & Periodontia & $\begin{array}{c}\text { Odonto } \\
\text { Saúde Col. }\end{array}$ & $\begin{array}{c}\text { Bucomaxi- } \\
\text { lofacial }\end{array}$ & $\begin{array}{c}\text { Tecnico } \\
\text { Higiene Dent. }\end{array}$ & $\begin{array}{l}\text { Odonto- } \\
\text { pediatria }\end{array}$ & TOTAL \\
\hline CUSTOS DIRETOS & & & & & & & & & & \\
\hline Salários e Encargos Médicos/Odonto & & & $3.958,86$ & $11.571,39$ & $7.020,25$ & $25.431,81$ & $9.102,00$ & $10.811,00$ & $12.815,94$ & $80.711,25$ \\
\hline CUSTOS INDIRETOS & & & & & & & & & & \\
\hline Salários e Encargos Coord.recepção & $8.330,36$ & n.atendimentos & 138,72 & 264,52 & 156,81 & 955,24 & 149,92 & 209,95 & 164,86 & $2.040,01$ \\
\hline Estagiários & $2.436,63$ & n.atendimentos & 40,58 & 77,37 & 45,87 & 279,41 & 43,85 & 61,41 & 48,22 & 596,70 \\
\hline Salários e Encargos Recepção Odonto & $3.342,44$ & n.atendimentos & 227,28 & 433,39 & 256,93 & $1.565,11$ & 245,64 & 343,98 & 270,11 & $3.342,44$ \\
\hline Mat.Consumo Odontologia & $13.727,96$ & n.atendimentos & 933,49 & $1.780,02$ & $1.055,25$ & $6.428,16$ & $1.008,87$ & $1.412,80$ & $1.109,37$ & $13.727,96$ \\
\hline Salários e Enc.Gerência, Coord.med. e odo & $18.656,63$ & n.atendimentos & 248,59 & 474,02 & 281,02 & $1.711,83$ & 268,66 & 376,23 & 295,43 & $3.655,77$ \\
\hline Material de Expediente & $7.105,77$ & n.atendimentos & 94,68 & 180,54 & 107,03 & 651,98 & 102,33 & 143,30 & 112,52 & $1.392,38$ \\
\hline & & N.Atendimentos & 483 & 921 & 546 & 3.326 & 522 & 731 & 574 & $7.103,00$ \\
\hline & & $\%$ & $1,33 \%$ & $2,54 \%$ & $1,51 \%$ & $9,18 \%$ & $1,44 \%$ & $2,02 \%$ & $1,58 \%$ & 0,20 \\
\hline Salários e Encargos Serv.Limpeza & $8.212,25$ & área & 109,85 & 230,17 & 115,08 & 423,72 & 83,70 & 109,85 & 125,55 & $1.197,91$ \\
\hline Aluguel & $18.540,33$ & área & 248,01 & 519,63 & 259,82 & 956,60 & 188,96 & 248,01 & 283,44 & $2.704,46$ \\
\hline Manutenção e Conservação & $12.031,40$ & área & 160,94 & 337,21 & 168,60 & 620,77 & 122,62 & 160,94 & 183,93 & $1.755,01$ \\
\hline Seguro & 150,36 & área & 2,01 & 4,21 & 2,11 & 7,76 & 1,53 & 2,01 & 2,30 & 21,93 \\
\hline Vigilância & 587,31 & área & 7,86 & 16,46 & 8,23 & 30,30 & 5,99 & 7,86 & 8,98 & 85,67 \\
\hline Material de Limpeza & $3.149,38$ & área & 42,13 & 88,27 & 44,13 & 162,49 & 32,10 & 42,13 & 48,15 & 459,40 \\
\hline IPTU & $1.360,27$ & área & 18,20 & 38,12 & 19,06 & 70,18 & 13,86 & 18,20 & 20,80 & 198,42 \\
\hline Água & 350,28 & área & 4,69 & 9,82 & 4,91 & 18,07 & 3,57 & 4,69 & 5,35 & 51,09 \\
\hline Depreciação/Amortiz & $17.359,27$ & área & 232,21 & 486,53 & 243,27 & 895,66 & 176,92 & 232,21 & 265,38 & $2.532,18$ \\
\hline & & Área & 5,72 & 11,98 & 5,99 & 22,05 & 4,36 & 5,72 & 6,53 & 62,34 \\
\hline & & $\%$ & $1,34 \%$ & $2,80 \%$ & $1,40 \%$ & $5,16 \%$ & $1,02 \%$ & $1,34 \%$ & $1,53 \%$ & 0,15 \\
\hline Energia Elétrica & $16.943,22$ & Kw instalado & 307,71 & 644,73 & 322,37 & $1.186,89$ & 234,45 & 307,71 & 351,67 & $3.355,54$ \\
\hline & & Kw instalado & 53,86 & 112,84 & 56,42 & 207,73 & 41,03 & 53,86 & 61,55 & 587,28 \\
\hline & & & $1,82 \%$ & $3,81 \%$ & $1,90 \%$ & $7,01 \%$ & $1,38 \%$ & $1,82 \%$ & $2,08 \%$ & 0,20 \\
\hline Telefone & $3.196,73$ & setores c/linha & - & - & - & 266,39 & - & - & - & 266,39 \\
\hline & & Setores c/ramal & & & & 1,00 & & & & 1,00 \\
\hline & & $\%$ & $0,00 \%$ & $0,00 \%$ & $0,00 \%$ & $8,33 \%$ & $0,00 \%$ & $0,00 \%$ & $0,00 \%$ & 0,08 \\
\hline SOMA & $135.480,59$ & & $6.775,80$ & $17.156,40$ & $10.110,74$ & $41.662,37$ & $11.784,96$ & $14.492,27$ & 16.111,98 & $118.094,52$ \\
\hline Número de Consultas Possíveis & & & & & & & & & 604 & 739700 \\
\hline Número de Consultas/Exames Realizados & & & 483 & 921 & 546 & 3.326 & 522 & 731 & 574 & $7.103,00$ \\
\hline$\%$ Ociosidade & & & $5,3 \%$ & $1,0 \%$ & $7,1 \%$ & $0,0 \%$ & $3,9 \%$ & $18,4 \%$ & $5,0 \%$ & 0,41 \\
\hline Custo da Consulta Possível & & & 13,29 & 18,45 & 17,20 & 12,53 & 21,70 & 16,17 & 26,68 & - \\
\hline Custo da Consulta/Exame Realizados & & & 14,03 & 18,63 & 18,52 & 12,53 & 22,58 & 19,83 & 28,07 & - \\
\hline
\end{tabular}

Fonte: Elaborado pela autora com base em dados do Sistema ERP da Operadora 
Tabela 3 - Apuração do Custo dos Exames

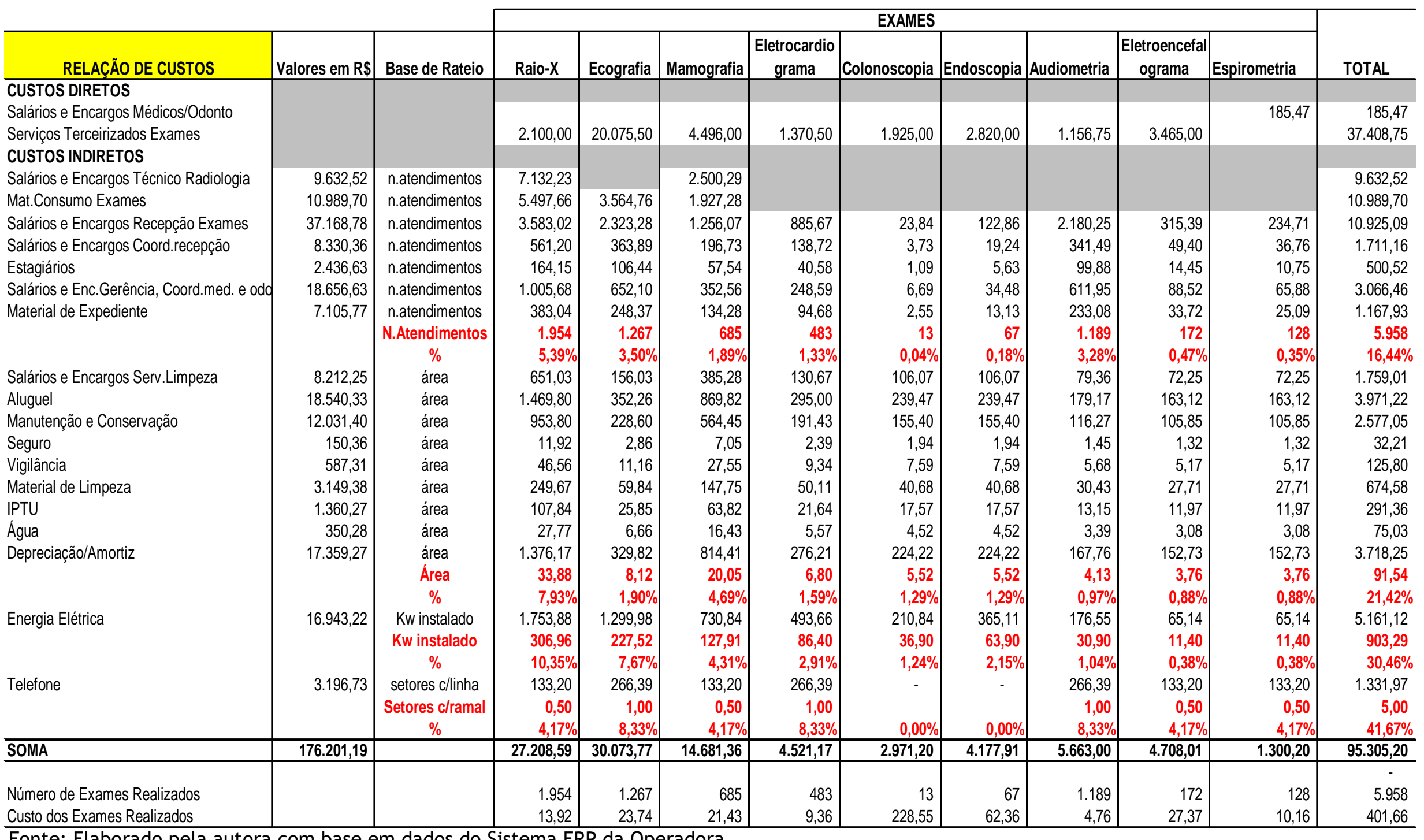

Fonte: Elaborado pela autora com base em dados do Sistema ERP da Operadora 

$\mathrm{Na}$ análise da Tabela 1 é possível identificar que, na especialidade de clínica geral, o custo da consulta realizada é de $\mathrm{R} \$ 18,70$ e uma ociosidade na agenda de consultas apenas de $0,3 \%$, o que garante o custo baixo da consulta. 0 clínico geral atende 24 horas do dia na unidade.

Já na pediatria, o valor de consulta é de $\mathrm{R} \$ 35,59$, devido à ociosidade de agenda de consultas de $58,2 \%$. Justifica-se essa ociosidade por haver plantão de pediatras durante 14 horas por dia, gerando maior volume de horários livres na agenda, principalmente durante à noite. Se a agenda fosse mais bem aproveitada, reduzindo-se o número de horas trabalhadas (base da remuneração) pelo pediatra, o custo da consulta poderia chegar a R\$ 14,88 .

Em reunião com o diretor administrativo da empresa para apresentação desse resultado, discutiu-se o motivo dessa situação na agenda da pediatria. Foi informado que é necessário oferecer essa especialidade por horário maior para casos de urgência, o que descaracteriza a ociosidade. Esse custo deve então ser administrado pela operadora como uma garantia de atendimento aos beneficiários.

A especialidade de ginecologia apresenta custo de consulta mais baixo comparativamente às outras especialidades, sendo apurado o valor de $\mathrm{R} \$ 10,78$ por consulta. A ginecologia é a especialidade que apresenta o maior número de consultas depois da clínica geral, ocupando $98,1 \%$ dos horários disponíveis para atendimento.

$\mathrm{Na}$ medicina do trabalho, que é a especialidade médica que faz os exames para admissão e demissão, o custo da consulta é de $R \$ 20,66$. Esta especialidade tem uma recepção exclusiva, havendo um plano específico para dar cobertura a esses atendimentos. A ociosidade existente é de $31,1 \%$, assim, se não aumentar o número de consultas com a maior utilização desse serviço, deve ser analisada a redução da carga horária dos médicos.

Para as consultas de cirurgia geral foi apurado o custo unitário de $\mathrm{R} \$ 21,54$, havendo uma ociosidade de agenda de $20,8 \%$. Essa especialidade é disponibilizada na rede própria por haver ambulatório equipado para a realização de pequenos procedimentos.

A especialidade de ortopedia e traumatologia atende apenas com hora marcada, não havendo plantão de urgência. 0 custo da consulta apurado para esta especialidade foi de $\mathrm{R} \$ 12,74$, com uma ociosidade baixa, de apenas 2,2\%. Depois da ginecologia, essa especialidade é a que apresenta o menor custo, devido principalmente a alta ocupação da agenda.

0 total de atendimentos de enfermagem realizados no período foi de 7.244 , o que representou um custo de R\$ 6,69. Nesse grupo são classificados todos os tipos de atendimentos efetuados pela enfermagem dentro do ambulatório, que pode ser um curativo, soroterapia, aplicação de medicamentos, colocação de tala gessada, etc.

Com as informações constantes da Tabela 1 é possível identificar:

a) As consultas com clínico geral apresentam a maior concentração de atendimentos da unidade de São Leopoldo. O volume de consultas dessa especialidade representa $55,7 \%$ do total de consultas.

b) A especialidade que apresenta o menor custo unitário é a ginecologia e a que apresenta o maior custo unitário é a pediatria.

c) 0 custo mais representativo em reais é das consultas de clínica geral, que apresenta o montante de $\mathrm{R} \$ 166.141,34$, representando $54,8 \%$ do custo com consultas médicas.

A Tabela 2 apresenta os custos da odontologia. Verifica-se que há uma variação maior no custo por tipo de atendimento do que a apresentada nas consultas médicas. Da mesma forma, o volume de atendimentos realizados também é menor. 
A especialidade de dentística, que trata de restaurações, tem um custo de $\mathrm{R} \$ 14,03$ por atendimento, apresentando uma ociosidade de agenda de 5,3\%.

A endodontia, que faz os tratamentos de canais, apresenta um custo mais elevado, no valor de $\mathrm{R} \$ 18,63$ por atendimento realizado, com uma ociosidade na agenda de apenas $1 \%$.

O custo do atendimento de periodontia, que trata a gengiva, é de $\mathrm{R} \$ 18,52$ por atendimento realizado. Essa especialidade apresenta uma ociosidade de 7,1\%, o que gera um acréscimo de custo em $7,7 \%$.

A odontologia em saúde coletiva é a clínica odontológica que faz o primeiro atendimento ao cliente para direcionamento, se necessário, a outra especialidade. É a especialidade que apresenta o menor custo da odontologia, e tem o maior número de atendimentos. Não apresenta ociosidade pois sua agenda está completa, devido principalmente a atendimentos de urgência, que são atendimentos extras feitos por essa especialidade odontológica.

A especialidade de bucomaxilofacial é a cirurgia odontológica, trata de lesões e traumatismos na cavidade oral. 0 custo da consulta desse profissional na rede própria é de R\$ 22,58, havendo uma ociosidade de 3,9\% na agenda.

O técnico em higiene dental faz a limpeza e aplicação de flúor. O custo dos atendimentos realizados é de $\mathrm{R} \$ 19,83$, havendo uma ociosidade de $18,4 \%$, o que torna o custo mais elevado. Se a agenda fosse completa, o custo desse atendimento seria de R\$ 16,17 .

A odontopediatria é a que apresenta o custo mais elevado da odontologia, no valor de $\mathrm{R} \$ 28,07$ por atendimento. A ociosidade dessa especialidade é de $5 \%$.

$\mathrm{Na}$ análise das informações constantes na Tabela 2 destaca-se:

a) O menor custo total é da especialidade de dentística, apesar disso, não apresenta o menor custo unitário da odontologia.

b) A especialidade de odontologia em saúde coletiva apresenta o maior número de atendimentos, e também apresenta o maior custo total. Apesar disso é a especialidade que tem o menor custo unitário.

$\mathrm{Na}$ Tabela 3 são apresentados os custos dos exames. Para os exames não há um controle rígido de agenda. Por causa disso, para não distorcer a informação, é apresentado apenas o número de exames realizados efetivamente, não sendo apresentada a agenda.

Os exames apresentam custo unitário maior para a operadora que as consultas médicas e a odontologia. 0 custo dos honorários para a realização de exames normalmente é por exame realizado, não havendo alteração de valor unitário se o volume de atendimentos for maior.

Alguns exames apresentam custo mais elevado devido à utilização de materiais na sua realização ou no seu diagnóstico.

$\mathrm{Na}$ análise dos dados da Tabela 3 destaca-se:

a) A ecografia é o exame de custo total mais elevado, no valor de $\mathrm{R} \$ 30.073,77$, representando $31,5 \%$ do total de gastos com exames. O custo unitário da ecografia é $R \$ 23,74$.

b) A espirometria é o exame que gera o menor custo total na unidade, no montante de $\mathrm{R} \$ 1.300,20$. O exame é realizado por um médico do trabalho e mede a capacidade respiratória do indivíduo, a um custo de R\$10,16 por exame. 
c) O exame de maior custo unitário para a operadora é a colonoscopia, devido ao valor pago ao especialista que realiza e interpreta esses exames. 0 custo unitário calculado para este exame é de $\mathrm{R} \$ 228,55$.

d) 0 exame que tem o menor custo unitário é a audiometria, no valor de $\mathrm{R} \$ 4,76$ por exame realizado. A audiometria é o exame que mede a capacidade auditiva e normalmente é realizado como exame para admissão de empregados.

e) 0 raio- $X$, bem como a mamografia, são exames que necessitam de um técnico para a sua realização. Além disso, também é pago honorários para o profissional médico que interpreta estes exames. 0 custo unitário do raio- $X$ foi calculado em $\mathrm{R} \$ 13,92$, com a realização no trimestre de 1.954 exames. Já a mamografia apresenta um custo unitário de $\mathrm{R} \$ 21,43$, com a realização de 685 exames. A variação significativa no custo desses exames refere-se aos honorários cobrados para a interpretação, os quais, no caso da mamografia, são maiores.

f) O eletrocardiograma, que é um exame cardiológico, apresentou um custo unitário de $\mathrm{R} \$ 9,36$, com a realização de 483 exames no período.

g) O eletroencefalograma, um exame que demonstra a atividade elétrica do cérebro, apresentou um custo unitário de $R \$ 27,37$. 0 gasto mais significativo desse exame são os honorários pagos aos serviços terceirizados para sua realização.

h) A endoscopia apresenta um custo de $\mathrm{R} \$ 62,36$ por exame realizado, havendo no período 67 exames.

\subsection{COMPARATIVO COM A REDE CREDENCIADA}

A rede credenciada é formada por profissionais terceirizados, contratados pela operadora para atender aos beneficiários do plano de saúde. Os contratos definem a forma de prestação do serviço e o montante a ser pago pelo serviço realizado.

Solicitou-se à administração da operadora a tabela de preços praticados pela rede credenciada vigente no exercício de 2007. Para a seleção dos credenciados foram utilizados os seguintes critérios:

a) foram selecionados os credenciados que oferecem os serviços disponíveis na rede própria;

b) optou-se pelos credenciados localizados na cidade de São Leopoldo, que é o local da rede própria. Quando o serviço não era disponível na cidade, foram selecionados os credenciados da cidade mais próxima;

c) havendo mais de um credenciado que presta o mesmo serviço na cidade, optouse pelo credenciado que oferece a tabela de menor custo para a operadora;

d) a operadora não contrata rede credenciada para a realização de atendimentos odontológicos. Assim, não há valores de serviços terceirizados definidos em contrato para esses atendimentos. Para fazer o comparativo da odontologia utilizou-se a tabela de preços que a Odontoprev repassa aos odontologistas em seu convênio. Essa tabela define o preço por tipo de atendimento e seleciona-se o preço do procedimento mais comum da especialidade.

O comparativo do custo do ambulatório com a rede credenciada não foi efetuado devido ao cálculo do custo geral, não compatível com os preços praticados pela rede credenciada. Por isso, não foi possível fazer esse levantamento, pois tais dados distorceriam os resultados apresentados, visto haver grande diferença de valores entre os tipos de atendimento. 


\section{Consultas Médicas}

$\mathrm{Na}$ Tabela 4, é apresentado o comparativo do valor das consultas médicas na rede credenciada com o custo apurado na rede própria. Observa-se que para efeito desse comparativo utilizou-se, como custo da Rede Própria, os valores das consultas efetivamente realizadas e não das consultas possíveis. Como o uso efetivo está abaixo da capacidade, esse custo está acima do que seria caso não houvesse ociosidade. Assim, temse aqui um procedimento conservador na avaliação comparativa com o custo da Rede Credenciada.

Tabela 4 - Comparativo de Valores das Consultas Médicas

\begin{tabular}{|l|r|r|c|r|}
\hline Especialidade & Custo em R\$ & Preço em R\$ & Variação & Variação \\
\hline & Rede Própria & Rede Credenciada & R\$ & \% \\
\hline Clínica Geral & 18,70 & 22,00 & $(3,30)$ & $-15,0 \%$ \\
\hline Pediatria & 35,59 & 25,00 & 10,59 & $42,4 \%$ \\
\hline Ginecologia & 10,78 & 22,00 & $(11,22)$ & $-51,0 \%$ \\
\hline Medicina do Trabalho & 20,66 & 20,00 & 0,66 & $3,3 \%$ \\
\hline Cirurgia Geral & 21,54 & 22,40 & $(0,86)$ & $-3,8 \%$ \\
\hline Ortopedia/Traumatologia & 12,74 & 22,00 & $(9,26)$ & $-42,1 \%$ \\
\hline
\end{tabular}

Fonte: Dados dos contratos de credenciados da operadora e dados da Tabela 1.

Com base nos dados apresentados na Tabela 4 constata-se que o custo na rede própria da operadora apresenta vantagem em comparação com a rede credenciada nas especialidades de clínica geral, ginecologia, cirurgia geral e ortopedia/traumatologia. Apenas nas especialidades pediatria e medicina do trabalho não é identificada vantagem em custo.

\section{Odontologia}

Tabela 5:

O comparativo de valores da odontologia com a rede credenciada é apresentado na

Tabela 5 - Comparativo de Valores da Odontologia

\begin{tabular}{|l|r|r|r|r|}
\hline Odontologia & $\begin{array}{c}\text { Custo em R\$ } \\
\text { Rede Própria }\end{array}$ & $\begin{array}{c}\text { Preço em R\$ } \\
\text { Rede Credenciada }\end{array}$ & $\begin{array}{c}\text { Variação } \\
\text { R\$ }\end{array}$ & $\begin{array}{c}\text { Variação } \\
\text { \% }\end{array}$ \\
\hline Dentística & 14,03 & 57,30 & $(43,27)$ & $-75,5 \%$ \\
\hline Endodontia & 18,63 & 86,50 & $(67,87)$ & $-78,5 \%$ \\
\hline Periodontia & 18,52 & 55,10 & $(36,58)$ & $-66,4 \%$ \\
\hline Odontologia Saúde Coletiva & 12,53 & 29,16 & $(16,63)$ & $-57,0 \%$ \\
\hline Bucomaxilofacial & 22,58 & 46,66 & $(24,08)$ & $-51,6 \%$ \\
\hline Técnico Higiene Dental & 19,83 & 32,40 & $(12,57)$ & $-38,8 \%$ \\
\hline Odontopediatria & 28,07 & 39,08 & $(11,01)$ & $-28,2 \%$ \\
\hline
\end{tabular}

Fonte: Dados dos contratos de credenciados da operadora e dados da Tabela 2.

Verifica-se que a odontologia apresenta vantagem em custo em todos os tipos de atendimento realizados na rede própria. 


\section{Exames}

Também foi elaborado comparativo do custo dos exames na rede credenciada, conforme apresentado na Tabela 6.

Tabela 6 - Comparativo de Valores dos Exames

\begin{tabular}{|l|r|r|r|r|}
\hline Exames & \multicolumn{1}{|c|}{$\begin{array}{c}\text { Custo em R\$ } \\
\text { Rede Própria }\end{array}$} & $\begin{array}{c}\text { Preço em R\$ } \\
\text { Rede Credenciada }\end{array}$ & $\begin{array}{c}\text { Variação } \\
\text { R\$ }\end{array}$ & $\begin{array}{c}\text { Variação } \\
\text { \% }\end{array}$ \\
\hline Raios-X & 13,92 & 11,96 & 1,96 & $16,4 \%$ \\
\hline Ecografia & 23,74 & 42,08 & $(18,34)$ & $-43,6 \%$ \\
\hline Mamografia & 21,43 & 35,00 & $(13,57)$ & $-38,8 \%$ \\
\hline Eletrocardiograma & 9,36 & 16,20 & $(6,84)$ & $-42,2 \%$ \\
\hline Colonoscopia & 228,55 & 262,79 & $(34,24)$ & $-13,0 \%$ \\
\hline Endoscopia & 62,36 & 284,17 & $(221,81)$ & $-78,1 \%$ \\
\hline Audiometria & 4,76 & 6,00 & $(1,24)$ & $-20,7 \%$ \\
\hline Eletroencefalograma & 27,37 & 37,80 & $(10,43)$ & $-27,6 \%$ \\
\hline Espirometria & 10,16 & 12,00 & $(1,84)$ & $-15,3 \%$ \\
\hline
\end{tabular}

Fonte: Dados dos contratos de credenciados da operadora e dados da Tabela 3.

O preço da ecografia e do raio- $X$ nos serviços credenciados variam por tipo de local examinado, ou seja, o raio- $X$ da perna tem um preço, o da coluna tem outro, o do braço tem outro. Na rede própria, não há diferença de preço, porque a incidência de gastos é a mesma. Assim, utilizou-se uma média de preços dos exames cobrados pelo credenciado selecionado.

Com a análise da Tabela 6, pode-se observar:

a) Os exames que apresentam vantagem em custo são: ecografia, mamografia, eletrocardiograma, colonoscopia, endoscopia, audiometria, eletroencefalograma e espirometria.

b) Apenas o exame de raio- $X$ apresentou custo maior para a operadora na rede própria em comparação com a rede credenciada.

Analisando os dados do comparativo com a rede credenciada observa-se que a rede própria, em um contexto geral, apresenta vantagens em custo para a operadora.

Além das vantagens em custo, ter uma rede própria é estrategicamente importante para a operadora. Em primeiro lugar, porque os beneficiários têm a garantia de atendimento de sua própria operadora; em segundo lugar, a operadora passa a ter poder de barganha de preços com a rede credenciada, pois não é dependente da sua rede credenciada.

A opção da operadora pelo não credenciamento de serviços terceirizados para atendimento odontológico, de acordo com os dados obtidos, é uma decisão acertada, pois qualquer tipo de atendimento odontológico apresenta custo maior na rede credenciada.

Enfim, a decisão estratégica da empresa em optar pela prestação de serviços através da rede própria, de acordo com este comparativo, é vantajosa. 


\section{CONSIDERAÇÕES FINAIS}

As operadoras de planos de saúde, devido à regulamentação governamental, enfrentam mudanças significativas no mercado de saúde suplementar. Nesse mercado concorrido, as operadoras que melhor se posicionam são as que possuem instrumentos úteis de decisão.

Este estudo teve como objetivo a elaboração de um sistema de custos da rede própria de uma operadora, a ser utilizado como instrumento de apoio à tomada de decisão.

O sistema foi estruturado com dados efetivos de uma unidade de atendimento da operadora, sendo obtidas diversas informações em nível gerencial como o custo unitário dos atendimentos, o custo total das consultas médicas, ambulatório, odontologia e exames, o número de consultas agendadas e realizadas, o número de atendimentos odontológicos realizados e agendados, o percentual de ociosidade da agenda, a comparação do custo unitário mensal.

De posse desses dados, o diretor da empresa pode acompanhar o desempenho da unidade e identificar quais são seus pontos críticos para atuar diretamente neles.

O sistema também pode ser utilizado com dados projetados, principalmente para definição de novos serviços a serem disponibilizados na rede própria, auxiliando no processo de planejamento estratégico e operacional da operadora.

Além do sistema de custos, este estudo também teve como objetivo a comparação entre o custo apurado na rede própria e o preço do serviço na rede credenciada, para identificar se a opção da operadora pela verticalização do serviço é mais vantajosa para a empresa. Trata-se, portanto, de um sistema com utilidade também para decisões estratégicas.

Outra contribuição do sistema desenvolvido está em auxiliar o gestor da operadora no processo de negociação de preços dos serviços com a rede credenciada, seja em novos contratos, seja em renovações de contratos já existentes. De fato, a partir do conhecimento dos custos da sua rede própria, a operadora tem parâmetros mais objetivos e eficazes para estabelecer uma base de negociação mais vantajosa.

Além do possível benefício econômico obtido com a redução de custos dos serviços contratados, deve-se, em igualdade de importância, analisar as questões qualitativas da rede credenciada. Ou seja, há que se analisar, com o mesmo rigor dado aos custos, a capacidade da rede credenciada em oferecer o serviço com, no mínimo, a mesma qualidade dos serviços prestados pela rede própria.

Finalizando, e considerando os aspectos de não sacrifício da qualidade do serviço prestado, tem-se que o sistema de custos é um instrumento gerencial importante para a operadora no mercado em que atua, que, se avaliado em conjunto com os preços praticados pela rede credenciada, auxilia a definir a melhor decisão estratégica: se voltada para a verticalização ou para a terceirização do serviço. 


\section{REFERÊNCIAS}

ALVES, S. L. Uma análise econômica da verticalização no mercado de saúde suplementar. REAH - Revista Eletrônica de Administração Hospitalar - FASC. v. 2, n. 6. Rio de Janeiro, set. a dez., 2006.

ANS - Agência Nacional de Saúde Suplementar. Resolução Normativa n. 27 de 3 de abril de 2003. Revisão do plano de contas da ANS. Disponível em: <http://www.ans.gov.br/portal/site/legislação>. Acesso em 10 jan. 2007.

ARAÚJO, W. Mercado atraente. Correio Brasiliense. Brasília, 30/10/2006. Disponível em: <http://www.fbh.com.br/index.php?a=not_namidia_temp.php\&ID_MATERIA=5577>. Acesso em 5 maio 2007.

BACIC, M. J. Escopo da gestão estratégica de custos em face das noções de competitividade e de estratégia empresarial. I Congresso Brasileiro de Custos. São Leopoldo, nov. 1994.

BRASIL. Lei n. 9.656, de 3 de junho de 1998. Regulamentação dos planos de saúde. Legislação Republicana Brasileira. Brasília, 1998. Disponível em: <http://www.ans.gov.br/portal/site/legislacao>. Acesso em 15 mar. 2006.

COSTA, R. G.; SANTOS, N. M. B. F.; SANTOS, R. F. dos. Gestão de custos: um estudo em empresas de medicina de grupo. Anais do XIII Congresso Brasileiro de Custos. Belo Horizonte, 2006.

FARIAS, L. O.; MELAMED, C. Segmentação de mercados na assistência à saúde. Ciência \& Saúde Coletiva. Rio de Janeiro, v. 8, n. 2, jan 2003.

FELICÍSSIMO, Â. Economia da saúde. Revista de Administração em Saúde, v.2, n.6, p.1316, mar 2000.

GADELHA, C. A. G. O complexo industrial da saúde e a necessidade de um enfoque dinâmico na economia da saúde. Ciência \& Saúde Coletiva, v.8, n.2, jan 2003.

GIL, A. C. Pesquisa social. São Paulo, Atlas, 1999.

GOMES, J. S.; SALAS, J. M. A. Controle de gestão - uma abordagem contextual e organizacional. São Paulo: Atlas, 1999.

HANSEN, D. R.; MOWEN, M. M. Gestão de custos - contabilidade e controle. 1. ed. São Paulo: Pioneira Thomson Learning, 2001.

HORNGREN, C. T.; FOSTER, G.; DATAR, S. M. Contabilidade de custos. $9^{a}$ ed. Rio de Janeiro, LTC, 2000.

MARTINS, E. Contabilidade de custos. 9. ed. São Paulo: Atlas, 2003.

MATOS, A. J. de. Gestão de custos hospitalares: técnicas, análise e tomada de decisão. São Paulo: STS, 2002.

MIRANDA, C. da R. Gerenciamento de custos em planos de assistência à saúde. Projeto ANS/PNUD. nov., 2003.

POMPERMAYER, C. B. Sistemas de Gestão de custos: dificuldades na implantação. Revista FAE, Curitiba, v. 2, n. 3, p. 21-28, set./dez., 1999.

PORTER, M. E.; TEISBERG, E. O. Redefining competition in health care. Harvard Business Review. v. 82, iss. 6, Jun., 2004. 
REZENDE, J. M. O uso da tecnologia no diagnóstico médico e suas conseqüências. Anais do XIV Encontro Científico dos Acadêmicos de Medicina da Universidade Federal de Goiás. Goiânia, 2002.

RIBEIRO, J. M. Restrições de informações, custos de transação e ambiente regulatório em saúde suplementar. Regulação \& Saúde. Rio de Janeiro, 2004.

VARTANIAN, G. H. O método de custeio pleno: uma análise conceitual e empírica. 2000. Dissertação (Mestrado em Controladoria e Contabilidade) - Curso de Pós-Graduação em Controladoria e Contabilidade, Universidade de São Paulo, São Paulo, 2000.

WARREN, C. S.; REEVE, J. M.; FESS, P. E. Contabilidade gerencial. 6. ed. norte-americana. São Paulo: Pioneira Thomson Learning, 2001.

\section{ENDEREÇO DOS AUTORES}

Universidade do Vale do Rio dos Sinos

Centro de Ciências Econômicas

Av. Unisinos, 950 - Cristo Rei

Sao Leopoldo, RS - Brasil

93022-000 - Caixa-Postal: 275 